\title{
Learned helplessness: Noncontingent reinforcement in video game performance produces a decrement in performance on a lexical decision task
}

\author{
PAUL E. FOX and WILLIAM F. OAKES \\ Brooklyn College of the City University of New York, Brooklyn, New York
}

\begin{abstract}
Contingent subjects played a video game involving their firing a missle at an erratically moving target and receiving true feedback whenever they scored hits and misses. Noncontingent subjects played the same game but were yoked to contingent subjects, so that they received the same pattern of "hits" or "misses" as their yoked cohorts, independently of their own true accuracy. This was accomplished by having the target speed up or slow down to produce the required "hits" or "misses," without the subjects' becoming suspicious that the feedback was noncontingent. Control subjects were told that, because the machine was not working properly, they could not play the game. All subjects then completed the Multiple Affect Adjective Check List (MAACL) and were then presented with a lexical decision task. Ninety-two strings of letters were presented one at a time, and the subjects had to indicate as quickly as possible whether or not each was a word. Subjects then filled out a questionnaire assessing their feelings of helplessness, attributions, etc. Noncontingent subjects performed significantly more poorly on the lexical decision task than did the contingent or control subjects, who did not differ from each other. The control group showed less hostility than did the other two groups on the MAACL, but aside from that, none of the mood or cognitive measures differentiated the groups. Learned helplessness was thus demonstrated independently of the cognitive processes usually adduced to explain it.
\end{abstract}

In the typical learned helplessness (LH) experiment with humans, subjects are led to believe that reinforcement will be contingent on their behavior, but it turns out not to be. The aversive noise turns out to be uncontrollable (e.g., Glass \& Singer, 1972; Hiroto, 1974), the problems turn out to be insoluble (e.g., Hiroto \& Seligman, 1975; Koller \& Kaplan, 1978; Roth \& Kubal, 1975 ), or the experimenter's spoken word "good" occurs at random intervals independently of the subjects' behavior (e.g., Babad, 1972; Eisenberger, Kaplan, \& Singer, 1974). The LH effect is a subsequent deficit in performance on a different task, presumably produced by the noncontingent reinforcement in the previous task.

Oakes (1982a) and Oakes and Curtis (1982) have argued that since the subjects in such LH experiments are typically able to detect the noncontingency-indeed, most experimenters have assumed that the subjects must become aware that the reinforcement is occurring independently of their behavior-then there is fatal confounding inherent in the design of the typical human $\mathrm{LH}$ experiment. If it is possible that the subjects' awareness that they have been misled, duped, or lied to by the experimenter could produce feelings and/or emotions

Requests for reprints should be sent to: William Oakes, Department of Psychology, Brooklyn College of the City University of New York, Brooklyn, New York 11210. that could result in a subsequent performance deficit, then any such deficit found cannot unambiguously be attributed to the prior noncontingent reinforcement per se. It may instead be caused by the awareness of that noncontingency.

To eliminate that confounding, Oakes and Curtis (1982) devised a procedure that permitted them to provide either contingent or noncontingent reinforcement to their subjects without the subjects' being able to tell the difference. Subjects shot a light gun at a target in a brightly lighted room. Since they could not see the light beam from the gun, the only way they could tell whether they had made a hit or a miss was by the occurrence or nonoccurrence of a tone triggered by the light beam's activating a photoelectric cell in the bull'seye. Contingent subjects got veridical feedback triggered by the photoelectric cell. Noncontingent subjects were yoked with contingent subjects and got nonveridical feedback providing the same patterns of "hits" or "misses" as that received by their contingent cohorts.

Questionnaire data indicated that the noncontingent subjects were not aware of the noncontingency. They responded just as the contingent subjects did, feeling no more nor no less helpless, hostile, anxious, or depressed and making the same attributions for their degree of success. Performance on a subsequent anagrams task was, however, significantly worse for the noncontingent subjects than for the contingent subjects or for a no- 
target-shooting control group, which latter two groups did not differ from each other. Oakes and Curtis (1982) concluded that the noncontingent reinforcement, and not the subjects' awareness of it, had produced the performance deficit on the anagrams task.

In a second experiment, Oakes and Curtis (1982) used essentially the same procedures, but in addition manipulated the subjects' awareness of the noncontingency orthogonally to the actual contingency/noncontingency. This was done by having the experimenter tell half the noncontingent and half the contingent subjects, following their target shooting, that they had been receiving noncontingent feedback. This was, of course, true for the noncontingent subjects, but false for the contingent subjects. Subsequent performance on the anagrams task was significantly affected by whether the reinforcement had actually been contingent or noncontingent, but not by whether the subjects thought it had been contingent or noncontingent.

The Oakes and Curtis (1982) findings are threatening to the current cognitive LH theory of Seligman and his associates (Abramson, Garber, \& Seligman, 1980; Abramson, Seligman, \& Teasdale, 1978; Alloy \& Seligman, 1979). That theory holds that when the experience of noncontingent reinforcement produces a subsequent performance deficit it does so by generating in the subject the expectation that reinforcement will be noncontingent in the future. In order for that expectation of future noncontingency to be formulated, the subject must recognize that the reinforcement has been occurring noncontingently and make certain attributions regarding that noncontingency. If, as in the Oakes and Curtis experiments, the subjects are unable to recognize that the reinforcement is noncontingent, the cognitive LH theory provides no way that the noncontingent reinforcement can produce behavioral helplessness.

The present experiment followed the Oakes and Curtis (1982) experiments in that it involved the use of a task designed to permit reinforcement to be given to subjects either contingently or noncontingently, without their being able to tell the difference. This was accomplished in the present study by the use of a specially programmed video target-shooting game that permits hits and misses to occur either on the basis of the subjects' behavior or independently of it. The effect of noncontingent reinforcement in playing the video game was then assessed in performance in a lexical decision task, in which the subject was presented with a string of letters and had to decide whether or not they made a word. Both the video game and the lexical decision task were presented to the subject on a computer. The present experiment thus provided an opportunity to replicate the findings of the Oakes and Curtis Experiment 1 , using different tasks and procedures.

\section{METHOD}

Subjects were recruited from the Brooklyn College introductory psychology course subject pool with the restriction that they must have learned English as their first language. There were 90 subjects assigned, in rotation, to one of three groups as they arrived at the laboratory.

The two tasks, the first-phase video game task and the second-phase lexical decision task, were both presented to subjects, and all subject responses were recorded and printed out by a Radio Shack TRS-80 computer, consisting of a video screen, keyboard, interface, cassette recorder, and printer.

The subjects were assigned to the contingent (C), noncontingent $(\mathrm{N})$, or control (CT) groups on a rotating basis as they arrived at the laboratory. The first-phase task involved the contingent and noncontingent subjects' playing a video target game that was presented on the video screen of the computer. The object of the game was to time the launching of an intercepting missile (accomplished by depressing the space bar on the keyboard) so that its movement would lead it to intercept a target moving horizontally across the top of the screen. The subjects were told that the target moved at a varying rate and that it was very unlikely that they would hit the target on every trial. They were told that the game would continue until 100 missiles had been launched and that scoring would be based on the number of successful interceptions (hits) achieved. Each time the missile intercepted the target, the target "exploded" on the screen, thus signifying a hit. For subjects in the contingent group, the occurrence or nonoccurrence of the reinforcement (the "explosion") was contingent upon the subject's actual performance, and the pattern of hits and misses over the 100 trials was stored in the computer.

For subjects in the noncontingent group, the occurrence or nonoccurrence of the reinforcer was independent of the subject's actual performance. Each noncontingent subject was yoked with the preceding contingent subject, and the noncontingent subject received the same pattern of hits and misses as his or her yoked contingent cohort, whose pattern had been stored in the computer. The computer was programmed such that the target would slow down or speed up to produce the hit or the miss required on each trial, regardless of when the noncontingent subject launched the missile. Since the movement of the target was variable on all trials for all subjects, the increases and decreases in its speed of movement necessary to produce the required hits and misses were not detectable by the noncontingent subject. As a further safeguard against a subject's becoming suspicious, the computer would not permit the launching of a missile if the target had already moved so far to the right of the screen that a collision would be impossible unless the target moved backward. ${ }^{1}$

The yoking assured that each noncontingent subject received the same number and pattern of reinforcements as the yoked contingent cohort. Contingent and noncontingent subjects thus experienced the same degree of success or failure, and if the contingent subject improved with practice over the course of the 100 trials, so did the noncontingent subject. A criterion of 15 hits was predetermined as the minimum acceptable for contingent subjects, and only one student was eliminated from the experiment on that basis.

Following completion of the video game, contingent and noncontingent subjects were asked to complete the Multiple Adjective Affective Check List (MAACL) (Zuckerman \& Lubin, 1965). Control subjects, who did not do the target-shooting video task, began by completing the MAACL when they arrived for the experiment. All subjects were asked to "check off any and all words that describe how you feel right now" on the MAACL.

All subjects, contingent, noncontingent, and control, were then presented with the lexical decision task. They were told that they would be presented with a string of letters in the center of the video screen, and that it would be their task to decide as quickly as possible whether or not what they were seeing was an actual English word. If they decided that it was, they were to press the "Y" (for "yes") key on the keyboard as quickly as possible. If they decided that it was not, they were to press the "N" (for "no") key as quickly as possible. The 
subjects were told that the computer would be recording the amount of time it took them to make a response once a letterstring had been presented, as well as the accuracy of that response. They were also told that each stimulus item in the list of 92 would be preceded by an asterisk, which would function as a ready signal. The duration of the asterisk was generated randomly for each trial and ranged between .5 and 3 sec. Once a letter string had been presented, it remained on the screen until a response had been made. The computer recorded, on a trial by trial basis, the latency of the subject's response (in units approximately equivalent to fiftieths of a second) as well as the accuracy of the response. Three counterbalanced versions of the list were rotated among the subjects within a given group. The computer printed out a record of the subject's performance following the last response.

Following the lexical decision task, all subjects were given a questionnaire to complete. This was the same questionnaire used by Oakes and Curtis (1982), in which the first three questions referred to the target-shooting video game. Only the subjects in Groups $\mathrm{C}$ and $\mathrm{N}$ answered them. The first question asked the subject to predict, on a 7-point scale, how successful the subject thought he or she would be in the video game. The second question asked the subject to indicate, on a 7-point scale, how "doable" he or she thought the task of hitting the target was. The third question asked that subjects estimate the extent to which the outcome of the video game was attributable to their own ability, the difficulty level of the task, their own effort, chance or luck, and experimenter control. Since previous research had indicated that college students have a poor understanding of the term "experimenter control," it was defined for them as a "preprogrammed, preplanned, or otherwise predetermined outcome which could not be affected by (your) skill or effort." The remaining three questions were answered by all groups, and obtained self-report measures of how nervous the subject usually was on tests, how important they felt it was to do well on laboratory tests of the kind they had just completed, and how their interest in the lexical decision task changed while performing it.

\section{RESULTS}

Table 1 presents the means and standard deviations of the three groups on the two performance measures for the lexical decision task, number wrong, and decision time. It can be seen that, for both measures, the performance of the noncontingent subjects was worse than that of the control or contingent subjects. They made more errors, and it took them longer to make their decisions. Two planned comparisons were made in order to determine whether significant $\mathrm{LH}$ occurred. The first compared the performance of the contingent and control groups, to see whether contingent reinforcement in the video game might have influenced performance on the lexical decision task. That analysis tested the hypothesis $\mathrm{Mu}_{\mathrm{C}}=\mathrm{Mu}_{\mathrm{CT}}$. The contingent

Table 1

Performance on Lexical Decision Task

\begin{tabular}{lccccc}
\hline & \multicolumn{2}{c}{ Number Wrong } & & \multicolumn{2}{c}{ Decision Time* } \\
\cline { 2 - 3 } \cline { 6 - 6 } \multicolumn{1}{c}{ Group } & Mean & SD & & Mean & SD \\
\hline Contingent & 16.80 & 6.72 & & 53.52 & 16.61 \\
Noncontingent & 20.10 & 6.21 & & 79.94 & 35.79 \\
Control & 16.50 & 6.36 & & 61.20 & 19.12 \\
\hline
\end{tabular}

*In units of approximately $1 / 50 \mathrm{sec}$.
Table 2

Anxiety, Depression, and Hostility Scores From the MAACL

\begin{tabular}{|c|c|c|c|c|c|c|}
\hline \multirow[b]{2}{*}{ Group } & \multicolumn{2}{|c|}{ Anxiety } & \multicolumn{2}{|c|}{ Depression } & \multicolumn{2}{|c|}{ Hostility } \\
\hline & Mean & SD & Mean & SD & Mean & SD \\
\hline Contingent & 7.10 & 2.83 & 14.63 & 4.66 & 8.67 & 3.35 \\
\hline Noncontingent & 8.37 & 3.13 & 14.40 & 4.03 & 9.07 & 2.80 \\
\hline Control & 7.40 & 4.56 & 12.30 & 5.50 & 6.97 & 3.69 \\
\hline
\end{tabular}

and control groups did not differ significantly on either the number wrong $[\mathrm{F}(1,87)<1]$ or decision time $[F(1,87)=1.381, p>.20]$. The other planned comparison compared the contingent and control groups with the noncontingent group, to see whether noncontingent reinforcement in the video game influenced performance on the lexical decision task. That analysis tested the hypothesis $\left(\mathrm{Mu}_{\mathrm{C}}+\mathrm{Mu}_{\mathrm{CT}}\right) / 2=\mathrm{Mu}_{\mathrm{N}}$. The performance decrement for the noncontingent subjects was significant for both the number wrong $[\mathrm{F}(1,87)=5.750$, $\mathrm{p}<.02]$ and decision time $[\mathrm{F}(1,87)=15.912, \mathrm{p}<.001]$. A substantial $\mathrm{LH}$ effect was thus demonstrated.

Table 2 presents the means and standard deviations of the three groups on the three mood measures assessed with the MAACL: anxiety, depression, and hostility. The same planned comparisons that had been made for the performance measures above were made for the mood measures. The comparisons of the contingent and control groups showed that they did not differ with respect to anxiety $[F(1,87)<1]$ or depression $[F(1,87)$ $=3.595, \mathrm{p}>.05]$, but that the control group was less hostile than the contingent group $[\mathrm{F}(1,87)=3.980$, $\mathrm{p}<.05]$. The conparisons of the contingent plus control groups versus the noncontingent group showed that the noncontingent group did not differ from the others with respect to anxiety $[\mathrm{F}(1,87)=1.932, \mathrm{p}>.15]$, depression $[F(1,87)<1]$, or hostility $[F(1,87)=$ $2.870, \mathrm{p}>.05]$.

Questions 1 and 2 on the questionnaire were designed to provide evidence regarding subjects' awareness of contingency/noncontingency. Question 1 asked the extent to which the subject believed he or she could be successful while playing the video game, and Question 2 asked the extent that he or she believed that the task of hitting the target could or could not be done. Scores ranged from 1 (definitely not) to 7 (definitely yes). Mean scores were greater (i.e., in the direction opposite to that for awareness of noncontingency) for the noncontingent subjects, but the differences were nonsignificant, with both $p$ values $>.45$. This is the finding that would be expected if both the noncontingent and the contingent subjects were phenomenally contingent, that is, believed the feedback was veridical.

Question 3 had subjects attribute their degree of success in the video target shooting in terms of percentages among their own ability, their effort, chance or luck, difficulty of the task, and experimenter control (defined above). Here again, the contingent and non- 
contingent groups did not differ significantly on any of their attributions, with all $p$ values $>.10$.

The last three questions asked subjects how nervous they usually were on tests of any kind, how important it was for them to do well on laboratory tests of this sort, and how their interest in the word-recognition task changed while they were performing it. No significant differences were found among the groups on any of these questions, with all $\mathrm{p}$ values $>.05$.

\section{DISCUSSION}

The results of the present experiment are completely consistent with those of the two Oakes and Curtis (1982) experiments. Here again, a strong behavioral helplessness effect was demonstrated in the absence of the phenomenal experiences usually invoked to explain LH. Using a task that permitted subjects to receive noncontingent reinforcement without their recognizing that it was noncontingent, we found that the subsequent behavior of the subjects was affected by the prior noncontingent reinforcement without their exhibiting any differences from subjects who had contingent reinforcement with respect to the cognitions, moods, or attributions that previous research has found related to $\mathrm{LH}$.

The fact that the contingent and noncontingent subjects did not differ in their cognitions, moods, attributions, etc., would not be surprising to an observer who had watched them play the video game. Both contingent and noncontingent subjects played with the same intensity, reacted in the same way to hits and misses, etc. As far as they both were concerned, they were playing the same game and receiving the same ("contingent") feedback. The yoking procedure even assured that they had exactly the same degree and pattern of successes and failures. The observer would not expect them to have reacted differently to the video game.

The observer would probably be surprised to learn that the noncontingent subjects did more poorly on the lexical decision task as a result of the noncontingent feedback, which they thought was contingent. It is difficult for most of us to conceive of our performance on a cognitive task such as word recognition being influenced by something like noncontingent reinforcement of which we are unaware. The cognitive theory of Seligman and his associates clearly requires that when noncontingent reinforcement causes a subsequent performance deficit, it is through the mediation of certain cognitive processes: awareness of the noncontingent reinforcement, attribution of its cause to stable and global factors, and the formulation of the expectation of future noncontingency. If those processes cannot operate, the cognitive theory cannot accommodate the finding of a subsequent behavior deficit. The present experiment, as well as those of Oakes and Curtis (1982), provided all the necessary controls to establish that the deficit was caused by the noncontingent reinforcement. How, then, may these findings be explained, if not on the basis of cognitive processes?

Oakes and Curtis (1982) suggested that the LH produced in their experiments was an instance of "learned irrelevance" (Mackintosh, 1974), in which subjects experience their behavior as being uncorrelated with the occurrence or nonoccurrence of reinforcement, and thereby "learn to ignore" (Mackintosh, 1973) their behavior as predictive of the occurrence of reinforcement. Oakes (1982b) presented a set of postulates constituting an expectancy theory of animal learning from which the learnedirrelevance phenomenon may be derived, without appeal to cog- nitive or mentalistic processes. These are seen to be "automatic" conditioning processes that are not dependent upon cognitive or other mental processes in the dog, rat, pigeon, or sophomore. The suggestion, therefore, is that the LH produced in the present experiment resulted from such automatic conditioning processes without any necessary cognitive awareness on the part of the subject.

\section{REFERENCES}

Abramson, L. Y., Garber, J., \& Seligman, M. E. P. (1980). Learned helplessness in humans: An attributional analysis. In J. Garber \& M. E. P. Seligman (Eds.), Human helplessness: Theory and applications. New York: Academic Press.

Abramson, L. Y., Seligman, M. E. P., \& Teasdale, J. D. (1978). Learned helplessness in humans: Critique and reformulation. Journal of Abnormal Psychology, 87, 49-74.

Alloy, L. B., \& Seligman, M. E. P. On the cognitive component of learned helplessness and depression. In G. H. Bower (Ed.), The psychology of learning and motivation (Vol. 13). New York: Academic Press.

BABAD, E. Y. (1972). Person specificity of the "social-deprivationsatiation effect." Developmental Psychology, 6, 210-213.

Eisenberger, R., Kaplan, R. M., \& Singer, R. D. (1974). Decremental and nondecremental effects of noncontingent social approval. Journal of Personality and Social Psychology, 30, 716-722.

Glass, D. C., \& Singer, J. E. (1972). Urban stress: Experiments in noise and social stressors. New York: Academic Press.

Нiroto, D. S. (1974). Locus of control and learned helplessness. Journal of Experimental Psychology, 102, 187-193.

Hiroto, D. S., \& Seligman, M. E. P. (1975). Generality of learned helplessness in man. Journal of Personality and Social Psychology, 31, 311-327.

Koller, P. S., \& Kaplan, R. M. (1978). A two-process theory of learned helplessness. Journal of Personality and Social Psychology, 36, 1177-1183.

Mackintosh, N. J. (1973). Stimulus selection: Learning to ignore stimuli that predict no change in reinforcement. In R. A. Hinde \& J. Stevenson-Hinde (Eds.), Constraints on learning. London: Academic Press.

Mackintosh, N. J. (1974). The psychology of animal learning. New York: Academic Press.

OAKEs, W. F. (1982a). Learned helplessness and defensive strategies: A rejoinder. Journal of Personality, 50, 515-525.

OAKES, W. F. (1982b). The postulates of $\mathrm{ES}_{2}$ theory: An expectancy theory of animal learning. Academic Psychology Bulletin, 4, 301-334.

OAkes, W. F., \& Curtis, N. (1982). Learned helplessness: Not dependent upon cognitions, attributions, or other such phenomenal experiences. Journal of Personality, 50, 387-408.

Roth, S., \& Kubal, L. (1975). The effects of noncontingent reinforcement of tasks of differing importance: Facilitation and learned helplessness effects. Journal of Personality and Social Psychology, 32, 680-691.

Zuckerman, M., \& Lubin, B. (1965). Manual for the Multiple Affect Adjective Check List. San Diego: Educational and Industrial Testing Service.

\section{NOTE}

1. The authors wish to thank Norman F. Simenson, who programmed the video game to meet the requirements of this experiment.

(Manuscript received for publication November 9, 1983.) 